Families in Society: The Journal of Contemporary Human Services

Copyright 1994 Families International, Inc.

\title{
Crises That Threaten Out-of-Home Placement of Children with Emotional and Behavioral Disorders
}

Christopher G. Petr

\begin{abstract}
Children with serious emotional and behavioral disorders present strong challenges to families and professionals who attempt to care for them at home. This longitudinal, exploratory study examines the placementthreatening crises experienced by nine Minnesota families during an 18-month period. The findings encourage critical reevaluation of placement-prevention programs, highlighting the importance of informal support systems, longstanding family supports, attitudes of professionals, and the role of medications.
\end{abstract}

\begin{abstract}
C HILDREN WITH SERIOUS emotional and behavioral disorders present challenges to their families and communities. Challenging behaviors, together with inadequate supports and service systems, can negatively affect even the strongest families, eroding families' resolve to keep a child at home. Out-of-home placements range from temporary foster homes within the community to psychiatric care at state hospitals and residential treatment facilities far from home. Historically, American society has been ambivalent about the appropriate role of out-of-home and institutional placement for these children: Despite many community-based initiatives over the years, out-of-home residential placements have always flourished (Petr \& Spano, 1990).

When placement-prevention efforts fail, the costs to families, children, and society are high. Parents have reported dissatisfaction with professional attitudes and behaviors, the lack of family supports, the financial burden of treatment, and the widespread practice of requiring transfer of custody to the state in order to receive residential treatment (Collins \& Collins, 1990; Tarico, Low, Trupin, \& ForsythStephens, 1989). These practices can cause
\end{abstract}

families emotional pain and financial hardship. In placement, the children may develop new emotional problems caused by the trauma of separation from their families; in fact, some children may undergo several different placements before being reunited with their families. For society, costs include the financial burden of caring for children in expensive placements as well as further erosion of the family as a social institution.

In 1980, Congress enacted the Adoption Assistance and Child Welfare Act (P.L. 96272). This legislation endorsed the concept of permanency planning, the goal of which is to ensure a child's sense of continuity and stability in family relationships (Maluccio, Fein, \& Olmstead, 1986; Samantrai, 1992). The law required that states make "reasonable efforts" to prevent out-of-home placement. This reasonable-efforts requirement spawned various family preservation programs, some targeted at

Christopher G. Petr is Assistant Professor, School of Social Welfare, University of Kansas, Lawrence, Kansas. This article is based on research funded by grant \#H133B80046, National Institute of Disabilities Rehabilitation Research. 
families of children with emotional disorders. These programs were designed to prevent outof-home placement by providing brief, homebased services (Nelson, Landsman, \& Deutelbaum, 1990; Whittaker, Kinney, Tracy, \& Booth, 1990). Initial evaluations of these programs were highly encouraging, but more recent studies and critiques have raised questions about program effectiveness (Rossi, 1992; Wells \& Biegel, 1991). Funding mechanisms in the 1980s continued to create disincentives to keeping families together, and the Department of Health and Human Services failed to monitor and hold states accountable for the "reasonable efforts" requirement (Select Committee, 1990). Hence, the placement-prevention goals of P.L. 96-272 have not been realized: The number of children in placement as a result of emotional problems rose by $60 \%$ between 1983 and 1986 (Select Committee, 1990, p. 22).

Given this context, it is appropriate to explore what constitutes "reasonable efforts" to prevent the out-of-home placement of children with serious emotional and behavioral disorders. Maintaining children in their families is a strong social work and societal value that is supported by federal law and policy. A key element in the design and implementation of these programs is the requirement that they be family centered and based on the realities of life for these children and families (Collins \& Collins, 1990; Friesen \& Koroloff, 1990).

The purpose of the prospective, exploratory study described in this article was to understand better the perspectives and experiences of families as they cope with crisis situations that jeopardize keeping children in their homes. This information can generate hypotheses for subsequent research and can enrich the design of policies and programs by incorporating the client perspective into service provision.

\section{Methods}

This study is part of a larger research effort focused on parent perspectives on reasonable efforts to prevent placement of children with disabilities. In addition to children with serious emotional and behavioral disorders, the larger study included parents of children with devel- opmental disabilities and children dependent on medical technology.

The present study used focus-group interviews (Krueger, 1988) to obtain data and insights that might not be obtained from individual interviews. In focus groups, people are brought together to talk about a particular topic. The researcher presents the topic and supervises a carefully planned discussion designed to elicit group members' perceptions, insights, and explanations in the area of interest.

\section{Sample}

Parents were recruited through state service programs and disability organizations in the Minneapolis-St. Paul area. Because the participants were affiliated with disability organizations and resided in a state recognized for its progressive health, social welfare, and disability programs, the families were in a highly advantageous situation. The perspectives of informed and knowledgeable parents in a relatively progressive service system can help social workers in other states extend, modify, and improve their service systems.

From a pool of 99 persons who expressed interest in participating in the program, 39 parents were chosen ( 26 families with 40 children). By design, the sample included a mix of participants, including male and female parents; singleand two-parent families; biological, foster, and adoptive parents; and a mix of ages of children. Fifteen participants were male and 24 female. Eighteen biological-parent families cared for 21 children with disabilities, 5 foster families cared for 17 children with disabilities, and 3 adoptiveparent families cared for 3 children with disabilities. Thirteen of the children were $0-6$ years of age, 9 were $7-12$, and 18 were 13-21.

The participants were assigned to one of five groups: two groups for mental and developmental disabilities (12 families), two for emotional disorders (10 families), and one for families with a medically fragile child or children requiring life-sustaining technological support (4 families). Each participant parent received 40 dollars per session.

\section{Data Collection and Analysis}

Each group met for a total of four sessions. Sessions lasted for approximately two 
hours each and were held on weekends every six months from January 1990 to June 1991. The purpose of the first session was to obtain general information and to identify key issues and needs. The results of the first sessions have been reported elsewhere (Petr \& Barney, 1993).

The purpose of the second, third, and fourth sessions was to track each family's situation during an 18-month period, focusing particularly on issues related to out-of-home placement. The author moderated the discussions. A research assistant co-facilitated and tape recorded the discussions. After initial greetings, the moderator focused the discussion on six questions:

1. Have any situations occurred within the past six months that could or actually did lead to an out-of-home placement for your child?

2. Did you seek the assistance of a helping professional regarding the above situation?

3. What services, if any, did you receive?

4. Did the social services that you received assist you in preventing out-of-home placement of your child?

5. Has your child, within the past six months, been placed or remained in an out-ofhome setting?

6. If your family experienced no placementthreatening crisis, what has helped keep the situation stable?

Following the focus-group interview, the audiotapes were transcribed in their entirety. A content analysis was conducted with categories derived from the six questions above. These categories were description of crisis situations, description of helpseeking behaviors, professional response to help seeking, prevention of crisis, and outcome. A research assistant independently read and coded the transcripts; the assistant's ratings were reviewed and modified by the author, and discrepancies were reconciled in a joint meeting. These coded statements were then organized into narrative form, providing a summary of each family's 18-month experiences. Finally, to check on the accuracy of the analysis, narrative summaries were mailed in draft form to the participants and their feedback was incorporated into the final report.

\section{Results}

This article reports the findings from the second, third, and fourth sessions relative to the families of children with emotional and behavioral disorders ( 9 of 10 original families completed the study). Results from the other groups will be reported elsewhere (Petr \& Murdock, in press). Each family's situation, as it unfolded during the 18 -month period, is summarized in brief, narrative vignettes. For the purposes of this study, a crisis was defined as any event or situation that threatened to result in out-of-home placement of the child. The family vignettes incorporate concepts from crisis-intervention theory (Aguilera \& Messick, 1978), including identification of the stressful event(s), the effect of the event(s) on family equilibrium, and the balancing factors that affected how the family coped and influenced whether the stressful event led to a crisis severe enough that the family considered out-of-home placement of the child. Additionally, the crisis-precipitating events are described as system induced, child condition or behavior, parent incapacity, general stress, or some combination of these types. Thus, the vignettes help us understand the relationship between stressful events, the family's help-seeking behavior, professional response, and crisis resolution. Names of participants have been changed to protect confidentiality.

All of the children in these sample families appeared to be at high risk for out-of-home placement. All nine families experienced at least one major crisis that threatened to precipitate placement during the 18 -month period of the study. During the first six months, seven families reported such crises; during the second six months, six families; and in the final six-month period, two families.

In four of the nine families (families 1, 2, 3 , and 4), the crisis resulted in an out-of-home placement. Of these four placements, one was a brief hospitalization, whereas the other three were for periods of months in multiple placements. Each of the other five families experienced at least one crisis that threatened to cause a placement during the 18 months, but all five families remained intact. 
Families in Society

April 1994

\section{Families with Children Placed Out-of-Home}

Family one. Family one consisted of Phyllis, a white, single, divorced mother of three; her biological son Herman, age 22; Rebecca, a 15-year-old girl from India adopted at age 3; and Archie, a 16-year-old Vietnamese boy adopted at seven months. Rebecca had a serious emotional disorder, had been diagnosed with post-traumatic stress disorder, and was hearing impaired.

Historically, American society has been ambivalent about the appropriate role of out-of-home and institutional placement for children. Despite community-based initiatives over the years, out-of-home residential placements have always flourished.

The crisis for the family during our study focused on Rebecca, who was placed out-ofhome at Phyllis's request in February 1990 after a series of stressful events related to Rebecca's behavior of running away, sexually acting out, and stealing. This placement resulted after years of difficulties, which, in Phyllis's opinion, related to early childhood (preadoption) traumas, lack of bonding, difficulties in adjusting to Phyllis's divorce 10 years previously, and inadequate family resources. Phyllis felt she was blamed by professionals and that absence of potential balancing factors such as crisis-intervention services, respite care, and parent education left the family unable to cope, leaving her no choice except outside placement.

Phyllis was quite dissatisfied with the initial placements. Rebecca was sexually abused in her first group home and then was placed but removed from two other homes for sexual acting out and stealing. Phyllis had to advocate vehemently for Rebecca regarding her safety, therapy, and education. By January 1991, Rebecca had settled into a rural, religious, all-female group home with a positive therapeutic, educational, and parent-involvement program.

At the end of the study she was doing "exceptionally well" at the group home, and the long-term plan was for independent living. Phyllis did not think that reintegration was advisable because of Rebecca's age, her positive progress, her need for stability, and her inability to adapt to a family situation. Phyllis was helped to cope with her intense feelings of grief and loss by the continued respect and involvement afforded her by the system and through her strong belief that the continued placement was best for Rebecca.

Family two. Family two was a white, working-class family consisting of the mother, Betty; father, Bill; Rachel, age 20; and Lester, age 18. Lester had a long history of emotional problems and learning disability; his parents, partly because of professional disagreements and confusions over the years, resisted labeling him with any diagnosis. Over the course of the study, Betty and Bill struggled with forging their proper role in Lester's transition to adulthood. They wanted to be helpful and supportive but not encourage overdependence.

In June 1990, Lester graduated from high school and planned to go away from home to college. His parents noted his growing maturity and his focus on attending college as keys to preventing crisis situations. After struggling through his first semester at college, Lester experienced blackouts and anxiety, necessitating a two-day psychiatric hospitalization. After discharge, he tried again to go to classes but was unable to do so. He returned home and entered counseling, receiving an antidepressant that had positive results. He continued to live at home and planned to return to college. His parents were determined to follow the counselor's advice to treat Lester like an adult by allowing him to make decisions.

Family three. Family three consisted of two experienced foster parents, Emil and May, who provided foster care to up to seven abused and neglected children at any one time. This study focused on their experiences with Matt, a 14-year-old American Indian boy with complex behaviors and numerous diagnoses, including fetal alcohol syndrome, obsessive-compulsive disorder, and mild mental retardation. In a difficult and painful decision made near the end of our study, the family decided to have Matt placed outside their home, after having cared for him for five years. 
Matt was nearly placed at the beginning of the study, but three foster sisters accused him of sexually molesting them. The family acted cautiously, sought the help of police and social workers, and determined that Matt was not guilty. The family asked that the girl who was the main instigator of the false accusation be removed; she was returned to her mother's care. Then, during the latter part of 1990, Matt became involved with a rough group of peers. He refused to take his medications, which resulted in violent mood swings, and demanded to leave foster care. $\mathrm{He}$ was hospitalized twice; on both occasions the psychiatrist recommended long-term residential psychiatric treatment. Despite this recommendation, the family took Matt back on both occasions, the second time only with the promise of "intensive help" from child welfare. The family reported that "intensive" support amounted to phone consultations with inexperienced social workers who were frequently unavailable when needed, and eventually a third hospitalization was required. This time, on the advice of the psychiatrist, the family decided not to take Matt back due to his increasingly violent and self-destructive behavior and the failure of the child welfare system's promise of intensive help. Later, the family learned that Matt had bounced from foster homes to psychiatric wards but had had no permanent placement.

At the end of the study, the family were considering having Matt return to their care, but only if he wanted to and only if specific intensive supports were in place prior to his return. These supports included help in administering and monitoring numerous medications; concrete, age-appropriate education regarding sexuality and daily living skills such as how to take a bus and purchase items; vocational training; and in-home personnel to provide respite and behavioral management.

Family four. Family four was a white, working-class family composed of the mother, Susan; 13-year-old Missy; and 15-year-old Jane, who was diagnosed with schizoid personality disorder. Jane's behaviors included extreme withdrawal, which manifested in refusal to attend school, to participate in activities, and to maintain personal hygiene.

Prior to our study, Jane had been in residential treatment for several months. After confirmed incidents of abuse at the facility, however, Jane was suddenly released to Susan's care. The staff had recommended therapeutic foster care, but placements were not available. In June 1990, Susan reported that therapists refused to treat Jane on an outpatient basis. Because lack of services and Jane's continued deterioration (manifested in behavior such as urinating and defecating on herself at school), Susan filed a petition with the court for placement. The judge ordered a complete psychological evaluation, and Jane eventually was placed in residential treatment in September 1990. After three months, the facility discharged her back home because she refused treatment and was not progressing in the program. This time, however, the county offered more in-home support, including in-home family and individual counseling. Despite some improvements in the area of personal hygiene, Jane refused to leave the house, isolating herself in her room or the bathroom. In March 1991 Jane was again placed-this time in a highly structured group home.

Meanwhile, Jane's sister, Missy, was also placed out of home in a juvenile-justice center, after months of individual, family, and daytreatment sessions. Missy complained to police about abuse at home and requested foster care. She had attacked Susan and wrecked her mother's apartment in order to get placed. Susan was quite dissatisfied with the county's response to Missy; Missy's program was not integrated with Jane's and the county refused Susan's request for a specific in-home worker whom Susan had found helpful.

Because of her daughters' extremely challenging behaviors, Susan was not certain that any amount or kind of services would have prevented placement. She acknowledged her own parenting inadequacies, including abusive incidents and confused thought processes, but nevertheless was disappointed in the county's inadequate response to her needs as she defined them. She also questioned whether her children were any better off in state care.

\section{Families with Children Not Placed Out-of-Home}

Family five. Family five was a white, working-class family composed of the mother, 
Ruth, who had been separated from her husband, Tom, for one year at the start of the study; Sally, age 7; and Isaac, age 11, who was diagnosed with attention-deficit hyperactivity disorder (ADHD), thought disorders, and obsessive-compulsive disorder.

Ruth reported having many stressful events in her family's life. The stressful events reached placement-threatening, crisis proportions at the beginning of the study, when a change in insurance provider resulted in a one-month suspension of Isaac's individual therapy. During that month, Isaac's difficult

When placement-prevention efforts fail, the costs to families, children, and society are high, and children may develop new emotional problems caused by the trauma of separation from their families.

behaviors escalated-he heard voices, washed his hands continuously, changed his clothes frequently, avoided bathrooms because of his fear of germs, and questioned whether foods and liquids were safe to eat and drink. Ruth felt powerless, frustrated, and "dehumanized" in her efforts to get therapy reinstituted and she worried that the new insurance company would insist that she transfer Isaac to a new therapist. Ruth wanted respite care, but it was not readily available, and she didn't have the energy to fight the system to try to obtain it. The crisis was resolved when the insurance company agreed to allow the original therapist to continue and Isaac's behavior stabilized.

Throughout the remainder of the study, Ruth managed to deal successfully with numerous stressful situations before they reached crisis proportions. She and her husband experienced ongoing tensions around their separation and probable eventual divorce, and she was left to fight her child's battles alone. Isaac's schoolteacher at one point wanted to place Isaac out of school in a homebound educational program because of a persistent, disruptive cough, but Ruth resisted. Sally began to act out, and Ruth was able to arrange individual and then group counseling for the girl. Ruth reported that the continuity of therapy, Isaac's medications, support from her family, and her determination to deal with problems when they first surfaced, helped her avoid crises.

Family six. Family six was composed of the mother, Dee; father, John; and three children. The oldest, nine-year-old Martin, had a learning disability as well as emotional/behavioral problems that had been diagnosed as attentiondeficit disorder. Martin had two younger sisters.

Over the course of the study, the family reported that they were confused and frustrated with Martin's behaviors and with school personnel. Martin had frequent temper outbursts, during which he would throw chairs and hit other children. When he became frustrated with school, he often wet his bed at night. Dee and John viewed Martin's problems as stemming from the academic stress associated with his learning disability but school personnel and other professionals tended to focus on his behavior and blame the family dynamics.

When the family reached a crisis point approximately midway through the study, Dee and John desperately wished they could call for respite care and in-home crisis management. But because they lacked knowledge about how to proceed and had had prior negative experiences with the system, they worked through the crisis by relying on each other and by maintaining contact with a local parent advocacy and support organization. Although difficulties continued, Dee and John seemed to accept the struggles and disappointments as an inevitable part of having a child like Martin. Occasionally, they wondered if Martin would fare better in foster care because they believed that foster care would focus more on Martin's needs and less on trying to blame and change them as parents.

Family seven. Family seven was a white, working-class family composed of the mother, Debbie; father, Nathan; four-year-old Jennifer; and five-year-old Linda. Linda had pervasive development disorder, with frequent temper tantrums, refusal to be toilet trained, and muteness at kindergarten.

The family experienced a series of stressful events during the first six months of the study, during which they felt as though they "couldn't handle it for another minute." Linda's oppositional behaviors escalated, and the insurance 
company delayed approval of recommended therapy for six months. Despite the difficult situation, the family used one another and friends to cope with the most intense situations and did not need to call professionals for crisis-intervention services.

Over the course of the study, Linda's behaviors improved and her development progressed. The family attributed their success in averting crises to Linda's improvement and to the system of formal services and informal supports that helped them manage stress. These services and supports included increased respite care, coordination of services among professionals, professional respect toward the parents, a parent-support group, the ability to share responsibilities and work together, and their ability to nurture themselves as individuals.

Family eight. Family eight was a white, single-parent family consisting of Julie, a widow who had recently returned to college, and her 15-year-old son, Chris, who was diagnosed with depression, minimal brain damage, and learning disabilities.

Over the course of the study, Julie experienced two episodes during which she feared that Chris might have to be placed. In both instances, placement was averted because of Julie's assertiveness in mobilizing and maintaining helpful resources. Early in 1990, Julie had to be hospitalized for an illness at a time when Chris's paternal grandmother, Julie's prime source of respite and support, had just died. Also, Chris had gotten in a serious fight at school. To confront this crisis, Julie mobilized family resources and used the ongoing support of family and individual counselors. A new case manager was added for Chris after the fighting episode. During the second six months, stresses caused by Julie's poor health, financial pressures, conflicts in the extended family, the stresses of Julie's college work, and Chris's continued fighting again threatened to precipitate a placement. However, placement was averted because, in Julie's view, she and Chris were older and stronger and their maturity helped pull them through. With family and service supports and continued medication for Chris to combat his depression, the family was able to cope with stresses in the final six months of the study.
Family nine. Family nine, a white, professional family, consisted of the mother, Sara; father, Sid; and three adopted children. Mike, a 14-year-old Korean boy, had been adopted at six months of age. He had been diagnosed with ADHD and manifested stealing behaviors and violence toward his six-year-old brother, Abe.

Early in the study, the family considered placing Mike because of serious stealing incidents at school and his "accidentally" breaking his brother's leg while wrestling with him. Mike revealed that he had been sexually abused by a former mental health counselor, which outraged the parents and added additional stress to the family situation. Although Sara and Sid felt they had come close to reaching their limit with Mike, they stuck together and assertively obtained needed resources, including group counseling and family support. Also, they made sure Mike took his medication at the prescribed intervals. After Mike's continued incidents of stealing, violence toward Abe, and involvement in occult activities, Sara decided to seek placement. Placement was averted when Sid and Sara's parents offered additional support, convincing Sara to keep trying. Mike's therapist helped her understand that Mike's behavior was related to his past sexual abuse.

In the last six months of the study, Mike's situation improved. Although he still had violent outbursts directed at property, he was doing better at school and was more cooperative. According to Sid and Sara, medication, group sexual-abuse counseling, success in swimming and at school, peer involvement, and helpful teachers were key to Mike's success.

\section{Summary and Discussion}

This study focused on the crisis situations and events that threatened out-of-home placement for children with serious emotional and behavioral disorders. The parents' experience with and perspectives on the service system are important in informing professionals about "reasonable efforts" that might be initiated in order to prevent placements as mandated under P.L. 96-272. The parents' perspectives are individual constructions of reality, representing an important but not necessarily 
definitive portrayal of the service system. Because of the exploratory nature of the study, caution should be maintained in generalizing from the results. The sample families were white, middle-class residents of a progressive state, and thus do not represent all parents of children with emotional disorders. However, the results may provide direction and guidance for further critical exploration of "reasonable efforts" on behalf of this population.

All of the children in these sample families were at high risk for out-of-home placement; in fact, four children were placed out of home. The experiences of families one and two indicate that the goal of prevention of out-of-home placement is not necessarily appropriate or feasible in all situations. Thus, these placements do not represent failures. The experience of family two illustrates that brief hospitalization is sometimes necessary to stabilize a child's rapidly deteriorating functioning. In such situations, efforts to prevent placement may be inappropriate. The experience of family one demonstrates that, in some situations, parents and professionals agree that children are best served in out-of-home placements, after reasonable efforts to prevent placement have not succeeded.

However, the scenarios of families three and four illustrate that parents and professionals do not always agree upon what constitutes a "reasonable" prevention effort. Both families thought that more could and should have been done to prevent placement, whereas the professionals involved believed that long-term residential care was indicated. Although therapeutic, family-centered residential programs are likely always to be needed for some children, society will not know which children actually require such care until creative, well-funded, family-centered, placement-prevention programs have been implemented and evaluated.

The experiences of families five through nine offer insights about placement-prevention efforts that do work. These families experienced crises that threatened to cause placements, but all managed to remain intact. These families initiated various coping behaviors, including strong assertiveness and reliance on both informal and formal supports. Several themes and factors emerged in these five fami- lies, which, together with the experiences of the first four families, offer guidance for further exploration and development of innovative prevention programs for this population:

1. Informal supports, especially as provided by spouses, extended family, and support groups are vitally important to coping successfully. In times of acute crisis, parents turned first to family and friends for help, not to professional service providers. Spouses in two-parent families relied on each other for primary support. Single parents depended on extended family. Respite was viewed as concrete support that allowed the parent to obtain time for self-nurturing, but only family seven, because of the child's age, and family three, because of its foster-parent status, qualified for respite care as a formal service. Several families also mentioned the benefits of informal supports such as parent support and advocacy groups, whereby they felt understood and not alone as parents.

2. Families benefit from services that focus on prevention of crisis rather than on crisis intervention. The experiences of the sample families call into question the efficacy of popular family preservation programs based on a short-term, crisis-intervention model. Such models may be effective for other target populations, but families of children with serious and persistent emotional disorders appear to need more sustained support. Nearly all of these families needed long-term support: medical insurance, counseling, respite, special education, and vocational training. Parents spent a lot of time and energy attempting to arrange and sustain these services. Using case managers to develop and maintain these family supports might prevent crises and thus reduce the need for crisis-intervention services. The absence or discontinuance of these long-standing supports can, in fact, precipitate a crisis, as happened in family two.

3. The attitudes and values of professionals make a difference. Parents treasured competent therapists, social workers, physicians, and teachers who formed a long-term alliance with the family and did not blame parents for their children's problems. Parents valued professionals who respected their competencies and worked with them as partners rather than labeling them as dysfunctional and the cause of the problem. Often, families do not believe 


\section{Out-of-Home Placement of Children}

professionals are part of their support system, but rather feel they add to their stress. Professionals need training to help them develop empathy for the struggles faced by these parents in order to develop respect for their strengths. Training programs might utilize parents as trainers, requiring trainees to spend time with the families in their homes. Regular client satisfaction surveys could be used to monitor staff attitudes toward families.

4. Medications help. In five of the nine families, medication was a critical factor in helping the child remain at home. For families five and nine, whose children were diagnosed with ADHD, and for families two and eight, whose children were diagnosed with depression, medications were cited as having a dramatic positive impact. For family three, whose child was taking a variety of medications, the impact of medication was more mixed. The parents found it difficult to administer and monitor so many prescriptions, and the child resented taking them. Nevertheless, his refusal to take medications precipitated increased violent behavior and his eventual hospitalizations.

For some children, at least, medications can help avoid placement. Programs should incorporate trained pediatricians and psychiatrists into their assessment and treatment teams. This recommendation may spur controversy among families and professionals who believe that many children are misdiagnosed and improperly medicated or properly diagnosed and overmedicated. Some may assert that this recommendation lends credence to a biological model for the mental and behavioral disorders of children, as opposed to other models focused on dysfunctional family systems (Johnson, 1986).

Our sample families do not provide evidence for settling these controversies. Rather, the study confirms that these children are complex and challenging and that medication can be an effective means of treatment for at least some of them. Our findings suggest the need for further research that might clarify which types of disorders are biological in nature, and which are not so that the appropriate role of medication can be determined. In addition, the findings support training programs designed to educate physicians, helping professionals, and parents about the appropriate and inappropriate uses of medication.

\section{REFERENCES}

Aquilera, D., \& Messick, J. (1978). Crisis intervention. St. Louis: C. V. Mosby.

Collins, B., \& Collins, T. (1990). Parent-professional relationships in the treatment of seriously emotionally disturbed children and adolescents. Social Work, 35, 522-527.

Friesen, B. J., \& Koroloff, N. (1990). Family centered services: Implications for mental health administration and research. Journal of Mental Health Administration, 17(1), 13-25.

Johnson, H. (1986). Emerging concerns in family therapy. Social Work, 31, 299-305.

Krueger, R. (1988). Focus groups: A practical guide for applied research. Newbury Park, CA: Sage Publications.

Maluccio, A. N., Fein, F., \& Olmstead, K. A. (1986). Permanency planning for children: Concepts and methods. New York: Tavistock.

Nelson, K., Landsman, M. J., \& Deutelbaum, W. (1990). Three models of family-centered placement prevention services. Child Welfare, 19, 3-21.

Petr, C. G., \& Barney, D. (1993). Reasonable efforts for children with disabilities: The parent perspective. Social Work, 38, 247-254.

Petr, C. G., \& Murdock, B. (in press). Home care for children dependent on medical technology: The parent perspective. Social Work in Health Care.

Petr, C. G., \& Spano, R. (1990). Evolution of social services for children with emotional disorders. Social Work, 35, 228-234.

Rossi, P. H. (1992). Assessing family preservation programs. Children and Youth Services Review, 14, 77-92.

Samantrai, K. (1992). To prevent unnecessary separation of children and families: Public law 96-272-policy and practice. Social Work, 37, 295-302.

Select Committee on Children, Youth, and Families, U.S. House of Representatives. (1990). No place to call home: Discarded children in America (Report 101-395). Washington, DC: U.S. Government Printing Office.

Tarico, V. S., Low, B. P., Trupin, E., \& ForsythStephens, A. (1989). Children's mental health services: A parent perspective. Community Mental Health Journal, 25, 313-326.

Wells, K., \& Biegel, D. E. (1991). Family preservation services: Research and evaluation. Newbury Park, CA: Sage Publications.

Whittaker, J. K., Kinney, J., Tracy, F. M., \& Booth, C. (1990). Reaching high-risk families. New York: Aldine de Gruyter. 